\title{
LA CAPELLA DE MÚSICA DE LA SEU DE BARCELONA DES DE LA MORT DEL MESTRE FRANCESC VALLS (2-6-1747) FINS A L'ANY 1755
}

\author{
Josep Pavia I Simó \\ Investigador Titular Emèrit, Barcelona
}

\begin{abstract}
This work considers the history of the Musical Chapel of Barcelona's Cathedral from the death of the great Master and composer Francesc Valls to the year 1755, this date being imposed by space limitations, although afterwards it will have a continuity. It envisages to offer a view as close as possible to what the structure of the Musical Chapel was, together with its cultural structure. Human voices are above all distributed in different trades which have an important link with liturgy. We can see the human part of each limb, the economic difficulties of musicians and the administrative problems to overcome them. The huge musical patrimony we have inherited was created within this situation, and we intend to preserve it and promote it.
\end{abstract}

\section{Resum}

El present treball contempla la història de la Capella de Música de la Catedral de Barcelona, des de Ia mort del gran Mestre i compositor, Francesc Valls, fins a l'any 1755, aquesta darrera data imposada pel límit d'espai, encara que després tindrà continuació. Es pretén donar una visió el més aproximada possible del que fou l'estructura de la Capella musical, vertebrada alhora amb l'estructura cultual. Les veus humanes, sobre tot es troben repartides en diferents oficis que tenen alguna important actuació en la litúrgia. Hi trobem la part humana dels diferents membres, les dificultats econòmiques dels músics, les dificultats administratives, per tal de poder-los subvenir i, en mig de tot això, es produí el patrimoni musical immens que hem heretat i que pretenem conservar i donar a conèixer.

El present treball enllaça i mantè la mateixa línia d'investigació seguida en la meva tesi doctoral i en altres treballs meus, publicats o en imprempta ${ }^{1}$, i, en conseqüència, és continuació cronològica de tots ells. Per aquesta raó, m'abstindré de repetir certs conceptes iteratius, com pel que fa a la metodologia, tractament de textos, etc., ja que seguiré les mateixes normes. Hi trobareu,

1. Pavia i Simó, J., La Música a la Catedral de Barcelona durant el segle XVII, ed. Fundació Salvador Vives i Casajuana, Barcelona, 1986; id., "La Capella de Música de la Seu de Barcelona des de l’inici del s. XVIII fins a la jubilació del mestre Francesc Valls (14-3-1726)", CSIC, AnM 45, pp. 17-66, Barcelona, 1990; id., "La Música a la parròquia de Sant Just i Sant Pastor de Barcelona, durant el segle XVII", CSIC, AnM 48, pp. 103-142, Barcelona, 1993; id., Tonos de Francesc Valls (c. 16711747), i Vol. II (en imprempta).

Anuario Musical, 56 (2001) 
doncs, principalment, les notícies que fan referència als mestres, organistes, minyons cantors, altres cantors i als instruments i a les normes que regien la Capella. Aquestes notícies, encara que no són tan abundants i il·lustradores com un hom voldria, són suficients per donar una visió prou interessant del que fou la música a la nostra Seu, en aquest temps, sobre tot si l'enriquim amb altres notícies, pel que fa, per ex., a la ingent producció dels músics de la nostra Catedral, suara fa poc desconeguda ${ }^{2}$.

Quant al tractament dels documents, mantindré la màxima fidelitat paleogràfica, en la transcripció literal, tot puntuant o accentuant excepcionalment en aquells casos que presenten alguna dificultat i actualitzaré els noms propis, fora de les cites textuals.

Hi trobareu personatges, l'activitat musical dels quals s'havia iniciat en temps anterior al present treball i, en consequiència, està contemplada en algun treball anterior i, ara, s'anirà completant el coneixement de la seva biografia.

Sóc conscient que l'abundància de dates i notes al peu de pàgina que caracteritza aquesta mena de treballs i l'extensió condicionada dels mateixos, els resta aquella certa fluidesa que un hom voldria donar-los-hi i obliga a adoptar un estil més aviat lacònic, tot procurant donar, però, les notícies senceres i fent-ne la anàlisi corresponent.

El punt "ad quem" del present treball (a. 1755) no es refereix a cap esdeveniment especial, l'única raó és la de l'espai disponible, presuposa, tanmateix, la continuació, en el tractament cronològic de la història de la Capella de Música de la Catedral de Barcelona.

\section{La Capella de Música}

\section{Generalitats}

Noves Ordinacions per a la Capella de Música. A l'acta capitular del 9 de febrer de 1753 , hom llegeix que el canonge Alòs, presentà al Capítol, per a ser aprobades, unes noves Ordinacions per a la Capella de Música i el Capítol en féu comissió als canonges Ribera, Quintana, Clariana i al Protector dels Escolans, de les quals confesso que no en tinc cap més notícia, per ara ${ }^{3}$.

Sembla que, paral-lelament a les Ordinacions que preparava el Capítol, els músics en prepararen unes altres, com dóna a entendre l'acta capitular del 29 de març de 1753, a la qual es parla de les "Constitucions" dels músics i tracta del mateix assumpte que la del 9 de febrer, però la del 29, recull l'opinió dels canonges comissionats, els quals digueren que, pel que feia a l'aprobació de les Constitucions que presentaren els músics pel seu compte, hi trobaven algunes dificultats per aprobar-la. Tanmateix, el Capítol resolgué deixar a la discreció dels susdits comissionats la facultat de retocar les Constitucions preparades pels músics, de la millor manera que els semblés ${ }^{4}$.

2. Pavia i Simó, J., La Música en Cataluña, durante el siglo XVIII, Francesc Valls (1671c.-1747), CSIC, MME, vol. 53, Barcelona, 1997.

3. SIV. $21, f .12 v$.

4. SIV. $21, f .80$. 
L'1 de juliol de 1754, el canonge Quintana proposà, en la sessió capitular, que pel bon govern del Cor i per evitar abusos que s'hi observaven, considerava molt del cas, suprimir o afegir a les Constitucions del Cor allò que pugués semblar més convenient i se’n féu comissió als canonges Josep Quintana, Anton Rius i també a Tagell 5 . Tanmateix, no les he trobades, aquestes Ordinacions/Constitucions.

Altres notícies sobre el redreçament del Cor, he cregut més oportú posar-les a l'apartat de l'entonador.

Reducció de rendes, reducció de solemnitat. En alguna ocasió, perquè s'havia acabat la renda i en altres per una reducció al tres per cent, com s'anirà dient, es reduïren i, fins i tot es perderen algunes solemnitats de molta tradició a les catedrals, en moltes de les quals durà fins i tot ben entrat el segle XX.

Músics "seculars", o "no clergues". Els membres oficials de la Catedral tenien uns privilegis de franquícia - "franquesas de portas"-, i l'inspector responsable del control, demanà al Capítol, el dia 1 de setembre de 1749, la llista d'aquests oficials, principalment dels "seculars de la Capella", per fer-los aquesta gràcia i el Capítol resolgué que la hi donessin ${ }^{6}$. Tanmateix, sembla que era una gràcia que s'havia de renovar cada any. Per això, en diferents ocasions, en què segurament per descuit no es feia al seu temps, els músics interessats ho recordaven al Capítol. Així, doncs, trobem que, el 12 de maig de 1752, li demanaren que se'ls mantingués el privilegi de les franquícies, del qual ja havien fruït l'any anterior, el qual privilegi els compensava dels escassos salaris i profits que tenien. El Capítol considerà que la petició no tenia lloc, de moment ${ }^{7}$. El 17 d'octubre de 1755 , les demanaren un altre cop, però, aquesta vegada, ho feren directament al bisbe, el qual els

digué que ho havien de fer a travès del Capítol, qui, aquesta vegada, els prometé que procuraria donar-les-hi ${ }^{8}$.

Nona. El 14 de maig de 1751, el canonge Marquet, com a Arxiver, féu present que, donat que s'havia perdut enterament la renta subjecta a l'hora de nona del dia de l'Ascensió, calia decidir, si en endavant es celebraria la festa com s'acostumava. S'acordà, doncs, no celebrar la festa, però sí la nona, encara que només com els dies de festa ordinaris ${ }^{9}$. La mateixa qüestió es suscità, l'any següent, a la sessió capitular del 5 de maig, i ja es deixà, fins i tot, la celebració d'aquesta hora, per haver-se perdut tota la renda ${ }^{10}$.

Motets. El 20 de maig de 1751, es prengué l'acord que la Capella no cantés motets llargs, ja que el dia anterior, festa de l'Ascencsió, se'n cantaren diferents "contra lo estil", quant a la duració i acordaren notificar-ho al Mestre ${ }^{11}$.

\footnotetext{
5. SIV. 22, $f, 14 v$.

6. SIV. $20, f .154 \mathrm{v}$

7. SIV. $21, f .3$.

8. SIV. $22, f .105$.

9. SIV. 20,f. 251 v.

10. SIV. $21, f .1 v$.

11. SIV. 20,f. 252.
} 
Matines. El 4 de juny de 1751, els arxivers recordaren que la renda de les matines de Corpus, la qual era de 10 lliures, degut a la reducció, quedà en 6 lliures i, en conseqüència, calia prendre resolució, pel que feia a l'assistència, sobre tot a les matines de l'octava. Fou resolt que els arxivers, calculessin fins a on podia arribar la renda ${ }^{12}$, notícia que no em consta, ni quina fou la solució.

Festa de l'Assumpció. El 9 d'agost de 1751, els Arxivers feren notar que, en virtut de la reducció feta al tres per cent, s'havia de reduir també la festivitat de l'Assumpció i, per això, havien fet demanar com podia quedar. S'aprovà l'aplicació de la reducció corresponent i l'estat que els susdits senyors havien fet, el qual no consta ${ }^{13}$.

Pregàries per demanar la pluja. En certes ocasions de molta necessitat d'aigua, l'Ajuntament demanava, en nom dels pagesos, unes rogatives especials per la pluja, durant les quals i en diferents dies, es visitaven certs temples i monestirs, visites que s'anomenaven 'Cambres Angelicals" ${ }^{14}$, en les quals hi tenia una intervenció important la Capella de Música de la Catedral. La definició o descripció d'aquestes visites, no l'he trobada, fins a l'acta capitular del 8 de gener de 1753, en tractar de les pregàries per demanar pluja. En l'esmentada acta, a més de la descripció o definició d'allò que eren les "cambres angelicals", també parla de les "llagues" i les "ermites", les quals m'eren desconegudes, fins ara i sembla que eren, si fa no fa, com les "Cambres Angelicals", si bé aquestes tenien més anomenada, a les actes capitulars. L'acta diu així:

"Las Cambras Angelicals son set Igl.as, ques visitan à honor, y gloria dels set Goigs de Maria SS.ma; y son Valldonzella, S. Agusti, $\mathrm{N}^{\mathrm{a}}$. $\mathrm{S}^{\mathrm{a}}$ del Pi, Carme, Merce, Junqueras, $\mathrm{St}^{\mathrm{a}}$. Maria del Mar". "Las llagas, son, lo Hosp.l de St ${ }^{a}$. Creu, St. Fran.ch, Jerusalem, St ${ }^{a}$. Catharina, Montesion". Las Hermitas, son, St. Pere de las Puellas, St. Antoni Abat, Angells, Jesus extramuros; Y en est any de 1753, fent preg ${ }^{a}$. Per pluja, y anà lo Cap.l assistinthi tambe lo S.r Bisbe en la professó), Caputxins de dins Ciutat (q.e antes se anaba al MontiCalvari, vui destruit) Y ultimam.t à St. Fran.co de Paula"15.

Desordres, per part dels músics. El 29 de març de 1753, es tingué un Parlament, després de Completes, en el qual el canonge Ribera exposà que el Mestre de Capella havia anat a casa seva a manifestar-li que, en la festa de St. Tomàs, celebrada a l'església de Sta. Caterina, havia repartit els papers corresponents als membres de la Capella, d'acord amb allò que els PP. Dominics volien que es cantés i que el violinista mn. Capó i també mn. Tomàs Guixer, subdiaconal i tenor de la Capella, manifestà el seu desacord amb el Mestre Pujol, amb paraules injurioses fins al punt de provocar admiració en tots els qui eren a l'església, per causa dels desencerts dels dos cantors en contra del Mestre. Així mateix, digué l'esmentat Ribera que, abans de comunicar-ho al Capítol, havia fet d'altres diligències per assolir la veritat i que, no havent-se fiat d'aquells músics, escoltà molta gent que hi era present i també dos Pares Dominics, els quals afirmaren que tot havia succeït com

12. SIV. 20,f. $254 v$.

13. SIV. 20, f. 268v.

14. Pavia i Simó, J., "Calendari músico-litúrgic de la Catedral de Barcelona, a finals del s. XVII-inicis del s. XVIII", CSIC, AnM 55, pp. 99-153, Barcelona, 2000.

15. SIV. $21, f .63 \mathrm{v}$ 
ho havia exposat el Mestre, però que no sols això, sinó que per totes les esglésies, on assistia la Capella de la Catedral, es produïen desordres semblants, per la manca d'unió dels músics. El Capítol deixà en mans del propi Ribera, Degà de la Seu, la correcció d'aital excés i la imposició de les privacions que cregués oportunes ${ }^{16}$.

Anar a tocar en les òperes. El 12 d'abril de 1753, el canonge Alòs, Protector dels Escolans, demanà permís al Capítol, per tal que un músic de la Capella de la present església, pogués anar a tocar en les òperes i el Capítol resolgué que ningun músic hi pogués anar, ni a tocar ni a can$\operatorname{tar}^{17}$.

Decadència del cant. Una resolució capitular del 5 de febrer de 1753, fa pensar en una certa decadència del cant, o introducció d'interpretacions de la música, en desacord amb l'estil de la música d'església, per part dels entonadors. El Capítol volgué posar-hi remei i manà que s'advertís als entonadors que cantessin

"com pinta la solfa dels llibres, sens deixar nota alguna",

i amenaçà que acomiadaria aquells que contravinguessin aqueixa disposició ${ }^{18}$.

Augment de les distribucions. El 23 de juliol de 1753, es tractà de la possibilitat d'augmentar les distribucions per l'assistència a les diferents hores i s'arribà a un acord afirmatiu, mentre es mantinguessin els lloguers de les possessions del Capítol "â uns preus regulars" ", a fi de no sentir-se tan descompensats. Pocs dies després, això és, el 3 d'agost, el canonge Roig demanà, a partir de quin dia es donaria l'augment corresponent a cada hora de tèrcia, sexta i nona i es prengué l'acord de fer-ho, a partir del primer del mes corrent ${ }^{20}$.

Permisos. El 8 de novembre de 1754, el Capítol concedí llicència i presència, more solito, al Mestre de Capella, a l'Organista i a un Entonador, sense que s'expressi el motiu ${ }^{21}$.

Benedicció de campanes. El 21 de maig de 1755, es prengué l'acord capitular de donar una dobla bella als músics (a cadascú?), pel treball de la benedcció de les campanes, la qual dobla devia pagar la Caritat i el notari en llevà acta ${ }^{22}$.

Elements de la Capella de Música, a la mort de Valls. Encara que Valls tingué una relació més aviat escassa amb la Capella, després de la seva jubilació i, sobre tot, els darrers anys de la seva vida, com explico al treball del període anterior, tanmateix, em plau donar fe de l'estat de la susdita Capella, al temps de la mort del gran Mestre i compositor, d'entrada al present treball. Era aquest, d'acord amb el llibre de la Caritat citat al peu i en el qual encara apareix el Mestre Valls:

\footnotetext{
16. SIV. $21, f .79 v$.

17. SIV. $21, f .83 v$.

18. SIV. $21, f .72$.

19. SIV. $21, f .105 v$.

20. SIV. 21,f. $107 v$.

21. SIV. 22, f. $45 v$.

22. SIV. 22, f. 80 .
} 
Mestre de Capella: Josep Pujol.

Mestre de Capella jubilat: Francesc Valls.

Diaconal: Joan Campà.

Subdiaconal: Tomàs Guixer.

Dormitorer: Josep Gerivet.

Oficials menors:

Entonador?: Josep Presas i Anton Utger

Trompa: Josep Drument i Joan Miserachs.

Violó gros: Jordi Marquès.

Organista: Francesc Mariner.

Mestre d'orgues: Josep Buscà.

Contralt: Joan Feliu, Bernat Casademunt, Joan Bta. Coll

Manxaire: Ros.

Baixonista: Josep Capó, Joan Capó

Arxillautista: Josep Torrablanca.

Viola: Ignasi Baduell.

Violí: Gabriel Terri, Mariano Cortès, Joan Anton Capó.

Oboè: Joan Pradell, Tomàs Rossell.

Violó: Jaume Soler.

Entonador: Joan Boix, Josep Prat, Joan Garriga

Arpista: Joan Rossell.

¿? : Ramon Prats (entrà l'any 1731, com a subdiaconal, amb veu de contralt).

Escolans de cota de grana: Podrien ser, d'acord amb la pèrdua de veu de tiple: Mariano Oliveres (1747), Feliu Farré/Ferrer (1749), Pere Julià (1750) i Josep Puig $(1750)^{23}$.

\section{Mestre de Capella}

Francesc VALLS. Per tal de fer honor al títol del present treball, considero necessari recordar la circumstància del seu òbit, amb què vaig cloure el treball anterior. El 3 de juny de 1747, es tingué parlament en la sagristia, post officium, en el qual el president i vicari general Vilanova, comunicà lacònicament la defunció de Francesc Valls, Mestre jubilat de la Capella i beneficiat $\mathrm{i}$ que, per aquesta raó, els Infermers del Col·legi de Sant Sever -cal recordar que Valls estava agregat a la Germandat de Sepultures dels Beneficiats de Sant Sever-demanaren al Capítol el corresponent permís per sortir en processó de la Catedral, per anar a fer l'absolta al susdit difunt. El Capítol donà el permís, però digué que s'hi hauria d'anar post Completorium i sense tocs de campanes, per estar exposat el Santíssim. Els canonges anirien a cercar el cadàver, després de fer la reserva, a les sis de la tarda ${ }^{24}$. Això fa pensar que ocorreguè els dies de la vuitada de Corpus i, sense cap mena de dubte, la nit del 2 al 3 de juny.

23. Caritat. Albarans (en endavant: CA), 1745-1747, ff. 86-160v.

24. SIV. 20, f. $58 v$. 
Josep PUJOL, mestre. Les dades directes sobre el Mestre Josep Pujol, en aquest període, són escassíssimes, com es comproba pel que segueix.

Efectivament, el 12 de juny de 1751, el canonge Marquet comentà que el Mestre tenia una funció a St. Antoni de Pàdua i, al mateix temps, altra a l'Hospital i que, per poder-ho acomplir tot, ja que disposava de pocs elements, demanava que el diumenge infra-octava de Corpus, es cantés l'ofici de la Catedral a cant plà. El Capítol li respongué que de ninguna de les maneres i que procurés, quan tenia funcions en altres parts, que no fos la Catedral la pitjor servida ${ }^{25}$.

El 24 de setembre de 1753, es tractà de l'obligació que tenia el Mestre d'ensenyar de llegir, d'escriure i de solfa als escolans morats que en volien aprendre, atenent que per aquesta raó cobrava certa porció de la Sagristia i de la Manna. S'acordà recordar-li aquesta obligació i que, si no la volia cumplir, li seria retirat això que rebia d'especial ${ }^{26}$.

\section{Diaconal}

Pel que fa als Diaconals i Subdiaconals, s'acostuma de fer notar, als documents, que principalment eren tenor. També hi hagué algun contralt.

Joan CAMPÀ. El 15 de setembre de 1747, Campà demanà, com cada any, permís per anar a tractar-se, i el li concediren, com també la presència i la intenció de missa ${ }^{27}$.

El 17 de maig de 1748, el Diaconal Campà féu present al Capítol que, sumant la conveniència que cobrava i el que li donaren amb l'acta de perpetuació a fi d'ordenar-se, sumava 15 lliures anuals, les quals encara li devien, des de l'any 1730. Aquesta súplica fou comesa al Caritater ${ }^{28}$. El Capítol prengué 1'acord, després d'oir l'informe del canonge Caritater Morera, el dia 24 immediatament següent, de pagar, en endavant, a Campà les susdites 15 lliures que aquest reclamava, a més a més del salari ${ }^{29}$.

Les dades que segueixen fan referència, principalment, a la necessitat que tenia d'anar a prendre la brisa cada any. Així, doncs, el 27 de setembre de 1748, demanà llicència, en virtut de fe de metge i presència, les quals li foren concedides i també intenció de missa ${ }^{30}$. Igualment, el 26 de setembre de 1749, demanà el sòlit permís, presència i caritat de missa, acompanyant-ho de la corresponent fe de metge, per anar a prendre la brisa, a la qual súplica el Capítol resolgué annuir ${ }^{31}$. El 28 de setembre de 1750, demanà novament llicència per anar fora i intenció de missa, acompanyant la súplica amb fe de metge. Li concediren la llicència more solito, però quant a les misses ho encarregaren als Arxivers ${ }^{32}$.

\footnotetext{
25. SIV. 20,f. 257.

26. SIV. $21, f .116 \mathrm{v}$

27. SIV. $20, f .74$.

28. SIV. 20,f. $102 v$.

29. SIV. 20,f. 104 v.

30. SIV. 20,f. 120.

31. SIV. 20, f. 157.

32. SIV. 20, f. 207v.
} 
El 9 d'octubre de 1750, demanà augment de salari sobre les 10 lliures que cobrava, per poder assistir la seva mare i la seva germana, donzella. El Capítol li augmentà el salari fins a 25 lliures ${ }^{33}$.

El 6 d'octubre de 1752, mn. Joan Campà, tenor, obtingué permís novament, per anar â fora pera pendrer la brisa, amb dret a la presència, però sense la caritat de la missa. En aquesta ocasió, però, féu constar la seva condició de tenor i no la de diaconal, i el Capítol li remarcà que, en altra ocasió, fes constar en la súplica, la seva condició de Diaconal i no la de primer tenor ${ }^{34}$. El 17 de setembre de 1753, renovà la mateixa petició, la qual li fou concedida, juntament amb la presència $^{35}$. I el 13 de setembre de 1754 , en què també li concediren l'estipendi de missa, a més de la presència ${ }^{36}$. El 19 de setembre de 1755, li concediren la llicència i la presència, però no la $\operatorname{missa}^{37}$.

\section{Subdiaconal}

Tomàs GUIXER. El 6 d'octubre de 1752, fou portada al Capítol una súplica de Guixer, amb què manifestava que, essent fora dos mesos, recreationis causa, li havia sobrevingut un atac de pedra i demanava la presència. El Capítol resolgué que, per concedir-li-la, era necessària i suficient la presentació de certificat mèdic del lloc on es trobava, donant fe que era veritat el dolor de pedra i que li era necessari per a la salut no moure-se' $n^{38}$.

El 6 de juliol de 1753, aquest subdiaconal demanà permís per retirar-se a la vila de Ripoll, d'on era originari i tenia residència, però assegurà que només ho faria quan el Capítol tingués subjecte per a substituir-lo. Tot fent constar els 22 anys que havia servit la Catedral de Barcelona, demanà alguna subvenció, petició que fou comesa al Protector dels Escolans ${ }^{39}$. La resposta del Capítol no trigà gaire, ja que, l'11 del mateix mes, el canonge Ibarra, a qui s'havia encarregat la petició de Guixer, digué que aquest deixava el servei i l'ofici de Subdiaconal per motius de salut, com ho avalava el certificat mèdic presentat pel propi interessat. El Capítol deixà en mans del susdit Ibarra l'assignació d'una mòdica subvenció, la qual es concretà en 15 lliures $^{40}$.

Vuit dies després de l'acta anterior, això és, el 20 de juliol de 1753, el mateix Ibarra presentà els Memorials dels pretenents a la plaça de Subdiaconal i el Capítol el comissionà novament per a aquesta qüestió ${ }^{41}$, circumstància que afavorí la partença de Guixer. Efectivament, el 20 d'agost de 1753, vacant ja la plaça de Guixer, el canonge Ibarra, féu relació de les obligacions i salari que l'esmentat Guixer tenia, quan entrà al servei de l'ofici de Subdiaconal i proposà que el Capí-

\footnotetext{
33. SIV. 20, f. 209.

34. SIV. $21, f .42$.

35. SIV. 21,f. $114 \mathrm{v}$.

36. SIV. 22, f. 37.

37. SIV. 22,f. 101v.

38. SIV. $21, f .42 v$.

39. SIV. 21, f. 101v.

40. SIV. $21, f .104$.

41. SIV. $21, f .105$.
} 
tol determinés per la elecció de nou subjecte i, un cop feta aquesta, quina seria la conveniència del salari que li darien i què caldria fer, si sortís més d'un subjecte ${ }^{42}$.

Feliu HUMET. El divendres 11 de gener de 1754, el canonge Ibarra proposà que el Capítol ja podia fer elecció de Subdiaconal, però el Capítol decidí ajornar-ho fins al dilluns immediatament següent ${ }^{43}$. El dilluns 14, efectivament, fou presentada una súplica de Feliu Humet, el qual manifestava que servia interinament aquest ofici, d'ençà que el renuncià Tomàs Guixer i demanava la remuneració corresponent al temps servit i el nomenament amb el mateix salari de Guixer. El Capítol ho cometé al canonge Ibarra ${ }^{44}$ i la resposta li fou tornada el 18 del mateix mes i any, en la qual li recomanaven que continués servint l'ofici, fins a tant no fos provist i que, després, li satisfarien el treball vençut, a raó de 108 sous al mes ${ }^{45}$.

El mateix 18 de gener de 1754, es tractà de l'examen per als pretenents a l'ofici de Subdiaconal i fou resolt que el canonge Ibarra el convoqués, quan cregués més convenient, després de Completes i, amb l'assistència del Mestre, el/els fes cantar i informés el Capítol, pel que feia a les veus i idoneitat dels subjectes ${ }^{46}$. La primera notícia que he trobat, posteriorment, sobre aquest tema, correspon al dia 28 de gener següent, a la qual es diu que el canonge Ibarra féu relació dels oposats que s'havien examinat per a l'ofici de Subdiaconal i es resolgué que, el primer capítol següent, es faria la nominació ${ }^{47}$.

Gabriel TERRI. Com s'havia acordat el 28 de gener immediatament passat, l' 1 de febrer, es passà a cobrir la vacant de Subdiaconal. Es votà per capsa i en sortí elegit Gabriel Terri, prevere i primer violí que era de la Capella de Música $^{48}$. En el capítol del dia 4 de febrer, el canonge Marquet demanà, si es donaria a Terri la rossa que es donà a Guixer, quan fou elegit Subdiaconal i el Capítol resolgué que la hi donessin i, tot seguit entrà Terri a prestar l'acostumat jurament de servir bé i cumplir les obligacions i càrregues del susdit ofici ${ }^{49}$.

\section{Escolans}

No considero necessari repetir, ara, tota la introducció del capítol de la meva tesi corresponent als escolans. Tanmateix, perquè ho entenguin els qui la desconeixen, ho resumiré dient que, a la Seu de Barcelona, hi havia dos grups de minyons destinats al cant i al servei litúrgic. Un grup era de nois més grans, l'altre de nois més petits.

Els nois més grans eren quatre i llur tasca principal era cantar. Vivien a casa del Mestre de Capella i eren designats, d'acord amb llur vestimenta litúrgica, escolans o minyons de grana/de cota de grana. Aquests escolans rebien intensiu ensenyament musical i formació religiosa i huma-

42. SIV. 21,f. $111 \mathrm{v}$.

43. SIV. 21,f. $128 v$.

44. SIV. 21,f. $128 \mathrm{v}$.

45. SIV. 21, f. 129v.

46. SIV. 21, f. 129 v.

47. SIV. $21, f .132$.

48. SIV. 21, f. 133.

49. SIV. $21, f .134$. 
nística a casa del Mestre de Cant, essent ell qui els l'havia de donar. Quan acabaven la veu de tiple, la Catedral els donava l'ajut anomenat rossa, computable per dotze lliures i els donava dues rosses anuals, durant tres anys i, a més, els feia un vestit llarg. Molts d'aquests escolans continuaven al servei de la Capella de la Catedral i s'ordenaven d'ordes sagrats. Alguns esdevenien grans mestres i organistes d'aquesta o d'altres catedrals i/o parròquies i van deixar nombroses composicions musicals importants per a la història de la música. La procedència de molts d'aquests compositors, quant a llur formació musical, la qual restava suara desconeguda, és possible, a partir de l'estudi sistemàtic de les capelles musicals de les catedrals, parròquies i convents, principalment en el capítol dels minyons cantors.

Els nois més petits servien l'altar i es preparaven per rellevar els grans, quan aquests acabaven la veu. Del fet que n'eren dotze, hom dedueix que no tots esdevenien escolans de grana, sinó només els millors. Vivien amb llurs pares, si eren de Barcelona i amb parents o amistats, si eren de fora de Ciutat. Rebien les distribucions que els corresponien per llurs actuacions i, per referència a l'uniforme que usaven, eren anomenats minyons o escolans de cota morada. Dels escolans morats hi ha molt poques notícies, en comparació amb els de cota de grana.

\section{Escolans de cota de grana.}

Cotes de grana. Els vestits dels escolans es renovaven d'acord amb unes normes de periodicitat, tanmateix i, donada la penúria ecònomica de certs temps, de vegades els aprofitaven fins a l'extrem de cridar l'atenció, perquè eren molt vells.

El 6 de juny de 1755, el canonge Manuel Joven presentà al Capítol el compte de l'import de les cotes de grana que havia fet fer, el qual import era de 99 lliures, 18 sous i sis diners, i s'acordà que es paguessin de la Administració de la Caritat ${ }^{50}$.

Cotes negres. Els escolans de grana també vestien cotes negres. Possiblement, es tractava del vestit de carrer. El 21 de juny de 1747, es pagaren 59 lliures, 9 sous i 4 diners,

“per la valor del Paño vintysissè rafi negra p.r las cotas dels Escolans de Grana..."

El 18 de setembre de 1750, el canonge Marquet féu present que els escolans de cota de grana necessitaven cotes negres i el Capítol resolgué que es donés providència per fer-les ${ }^{52}$. El 5 d'octubre ja eren fetes i el Capítol estengué un Manament contra les Pabordies, perquè les pagues$\sin ^{53}$.

Altra petició de cotes negres per als escolans de cota de grana, la féu el canonge Ibarra, el dilluns 11 de març de 1754 i el Capítol li encarregà que ho solucionés ell mateix ${ }^{54}$.

50. SIV. 22, f. 83 .

51. SIV. $20, f .60 v$.

52. SIV. 20,f. $206 v$.

53. SIV. 20,f. 208v.

54. SIV. $21, f .140 v$. 
Noms i notícies d'escolans de cota de grana

Marià OLIVERES. El 13 de novembre de 1747, El Capítol resolgué donar-li, a petició del Mestre de Capella, lo acostumat, ja que havia acabat la veu ${ }^{55}$.

Feliu FARRÉ/FERRER. El 28 d'abril de 1749, el Mestre de Capella demanà per a ell la caritat que s'acostumava donar als escolans, quan acabaven la veu i el Capítol s'avingué a concedir$1 \mathrm{a}^{56}$.

Pere JULIÀ. Amb súplica presentada pel Mestre de Capella al Capítol, el dia 15 de juny de 1750, aquell demanava per a Julià, escolà de cota de grana que havia acabat la veu, la gràcia que s'acostumava de fer amb aquests escolans, grácia que el Capítol concedi ${ }^{57}$. Un rebut del sombrerer Galderich Reixach, signat per Pau Cuyàs, pre., el 2 de juliol de 1750, parla d'un barret que serví per Pere Julià, escolá que fou de Cota de grana ${ }^{58}$.

Francesc SALA. El 25 de novembre de 1746, el Mestre de Capella comunicà al Capítol que, aquest escolà, havia acabat la veu i demanava per a ell la gràcia que el Capítol feia a tots els qui acabaven la veu. El Capítol resolgué que li fos donat tot allò que s'acostumava donar als demés $^{59}$. (V. més endavant: Francesc SALA i Francesc ROSSELL i SALA).

Josep PUIG. El Mestre demanà per a ell, el dia 27 de novembre de 1750, l'almoina acostumada, en ocasió d'haver acabat la veu i el Capítol cometé la súplica al Protector de la Capella ${ }^{60}$.

Ambrós COROMINES. També aquest escolà rebé l'obsequi del Capítol, quan acabà la veu i a proposta del Mestre de Capella, el 17 de desembre de $1753^{61}$.

Anton PUIG. El Mestre de Capella comunicà al Capítol, el 13 de maig de 1754, que aquest escolà havia acabat la veu i demanava per a ell la caritat que el Capitol solia donar a aquests minyons. El Capítol la hi concedí, però, en la present ocasió, a càrrec de la Pia Almoina ${ }^{62}$.

Pau ESCARRÀ. El 4 de novembre de 1754, el Mestre Josep Pujol, amb súplica, demanà per a aquest escolà de grana, per haver acabat la veu, l'obsequi que el Capítol donava en aqueixes circumstàncies, gràcia que el Capítol concedí ${ }^{63}$.

\section{Escolans de cota morada}

Dels escolans morats, en aquest període, no se'n fa esment.

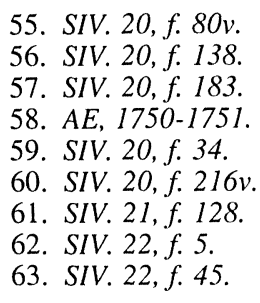




\section{Entonador-Dormitorer}

Generalitats. Sembla que els documents que comentaré sobre l'ofici d'entonador confonen/identifiquen aquest ofici amb el de dormitorer, fins a l'extrem de que un mateix document atribueix a una mateixa persona ambdós oficis.

Entonadors i redreçament del Cor. L'acta capitular del 18 de setembre de 1750, recull la proposta del canonge Anton Rius sobre la necessitat que hi havia al Cor d'entonadors, per trobarse malalts la major part d'aquests. El remei d'aqueixa situació, es deixà a mans d'una comissió formada pels canonges Marquet, Protector de la Capella, pel succentor Vilar i per Bessa ${ }^{64}$. Aquesta comissió, proposà una solució provisional, el 5 d'octubre del mateix any. Digueren que, per començar, si es volia redreçar el Cor, disposaven d'un beneficiat, el qual, sense cap salari, pujaria al faristol a cantar, fins a tant que el Capítol el considerés apte per portar el Cor. El Capítol, doncs, l'autoritzà de fer-ho, per habilitar-se ${ }^{65}$. Ja el 13 de novembre següent, el canonge Marquet féu present, que, aquest entonador, necessitava una almussa i sobrepellís, petició que el Capítol deixà a disposició del propi Marquet ${ }^{66}$. Els canonges de l'esmentada comissió, proposaren al Capítol, el 22 de gener de 1751, que l'entonador beneficiat admès per algun temps, els semblava apte, però que necessitava alguna subvenció. El Capítol decidí considerar-ho en la sessió següent, quan es tractaria del redreçament del $\operatorname{Cor}^{67}$, però no consta a l'acta d'aqueixa sessió.

El 21 de juny de 1751, el canonge Tagell denuncià, a més a més, la gran falta, tant d'entonadors, com de beneficiats, a l'hora de prima i el canonge Basteró proposà que els comissionats per a l'assumpte del Cor haurien de fer-ne relació, qüestions que foren ajornades per a un altre capí$\mathrm{tol}^{68}$.

El 5 de juliol de 1751, els senyors de la comissió per a cercar entonadors, encara no tenien presa una determinació i es parlà del desordre que hi havia al Cor, per causa dels propis entonadors. El Capítol recomanà als senyors de la susdita comissió, que s'afretessin a trobar-hi remei, altrament pensessin en la conveniència de posar edictes, si arribava l'ocasió ${ }^{69}$. Aquests comissionats, exposaren al Capítol, el 12 de juliol de 1751, que, després de pensar-ho millor, es decantaven per l'edicte per als entonadors i consideraven que la conveniència que s'hauria d'oferir, entre distribucions, salaris i útils de l'església, era d'unes tres centes lliures. El Capítol els encarregà l'elaboració del paper i que les tres centes lliures, no incloguessin l'útil de franquícia i indivís, i també, que la major part de les susdites tres centes lliures fos de distribucions i la resta en salari ${ }^{70}$. El canonge Morera, encara proposà si, a més de tot això que es plantejava, si es jubilarien, o no, altres i el Capítol respongué que, quan es posaria en pràctica, es tindria en compte aquesta consideració. El 19 de juliol 1751, els comissionats presentaren el paper de l'edicte, amb possibilitat de presentar-s'hi qui

64. SIV. $20, f .206$.
65. SIV. $20, f .208 v$.
66. SIV. $20, f .213 v$.
67. SIV. $20, f .225 v$.
68. SIV. 20,f. $258 v$.
69. SIV. 20.f. $261 v$.
70. SIV. 20,f. $263 v$.

142

(c) Consejo Superior de Investigaciones Científicas Licencia Creative Commons 3.0 España (by-nc)
Anuario Musical, 56 (2001)

http://anuariomusical.revistas.csic.es 
volgués i s'oferia la conveniència de 350 lliures, amb constància de les obligacions corresponents ${ }^{71}$. El 23 del mateix juliol de 1751, determinaren que el Secretari capitular signaria l'edicte, tot avalant la seva signatura amb el segell de la Catedral $^{72}$.

El 19 de novembre de 1751, els comissionats digueren que, després d'haver plantat els edictes, tan sols havien comparegut tres aspirants i que cap dels tres no era apte per governar el Cor i que, havent fet més diligències per diferents parts, no n'havien trobat cap altre més. Proposaren, doncs, que els semblava bé quedar-se amb els mateixos, però que, tenint en compte que Utger podia residir i Sebastià Alabaca (sic) era inútil enterament, semblava bé expel-lir-lo i donar de fix cent vint lliures als dos entonadors joves, això és, Josep Gomis i T. Mateu i alguna gratificació a Arabaca (v. més endavant: Sebastià Sanz, entonador), com també als altres dos per a vestir-se. Ho deixaren a la disposició dels susdits senyors comissionats ${ }^{73}$. El 31 de maig de 1752, el canonge Quintana proposà que encara hi havia poca assistència al Cor, a l'hora de prima, tant d'entonadors, com de residents i demanava que s'hi donés alguna providència, cosa que semblà molt bé al Capítol, el qual proposà un nou comissionat per al lloc que havia deixat, per defunció, el canonge Sala. El nou comissionat fou el canonge Basteró ${ }^{74}$.

El 26 de gener de 1753, els canonges comissionats per a la qüestió dels Entonadors del Cor, feren relació novament, d'alguns contrabaixos -enteneu-ho pel que fa a la veu, no d'instrumentsque s'havien examinat per a Entonadors, però que cap d'ells no els havia semblat apte. El Capítol els confirmà la comissió, però els recomanà que no admetessin per segona vegada cap d'aquests examinats $^{75}$.

\section{Noms i notícies dels Entonadors}

N. N. L'ocultació del nom del culpable, és una cortesia que he observat molt repetides vegades, en el comportament del Capítol. La present n'és una d'elles. En efecte, l'11 d'agost de 1732, dilluns, el canonge Josep de Sayol, féu present que mn. Rafel Genís se li havia queixat del fet que l'entonador N. (sic), s'havia negat a baixar a Sta. Eulàlia a cantar l'epístola, després de Prima, com tenia obligació i que ell, després de ser rogat, digué que no hi baixaria, perquè no en tenia l'obligació. El Capítol resolgué donar una reprehensió a l'entonador

"per lo mal modo de respondrer, y advertirlo per anavant"

Josep GERIVET. Apareix sempre com "Dormitorer", encara que era entonador. El 21 de juny de 1748, exposà al Capítol que la sobtada "desgana"que havia sofert i la subsegüent conva-

71. SIV. 20,f. $264 v$.

72. SIV. 20, f. 266v.

73. SIV. 20, f. $285 v$.

74. SIV. $21, f .12 v$

75. SIV. $21, f .69 v$.

76. SIV. 16, f. $145 v$. 
lescència, li havien ocasionat unes despeses que no podia cobrir, i demanava alguna assistència, súplica que el Capítol passà al senyor Protector ${ }^{77}$. El 28 de juliol de 1748, insistí novament en la petició d'alguna almoina, donat que la seva desgana l'impedia, fins i tot, de celebrar missa ${ }^{78}$. El 9 d'agost següent, el Capítol, informat de la gravetat de mn. Gerivet, fins al punt que els metges li havien recomanat els sacraments dels malalts, es resolgué que el Protector dels Escolans i el Secretari Capitular, decidissin com aconsolar-lo i ho executessin en la forma que els semblés més convenient ${ }^{79}$.

Superada la susdita gravetat, el 18 d'abril de 1749, exposà novament al Capítol, que, a més a més de les 18 lliures que li donaren l'any anterior, pels mesos de juny i juliol, en què no pogué celebrar missa, necessitaria alguna altra almoina, pel temps, en què tampoc no ha pogut celebrar des d'aleshores, petició que l'acta deixa sense resolució ${ }^{80}$, però se'n tractá a la del dia següent. En efecte, el 21 d'aquell mateix abril, els canonges Morera, i Sala explicaren amb detalls tot el que es referia a la malaltia de Gerivet i afegiren que aleshores ja es trobava reparat i en condicions de poder celebrar missa i opinaven que, a més de les 78 lliures que li donaren al principi de sa malaltia, n'hi podien donar altres 30 més, pel temps que ell reclamava, com a darrera gratificació. El Capítol ordenà que s'executés d'acord amb aquesta proposta ${ }^{81}$.

L'acta capitular del 5 de desembre de 1749 recull la resolució capitular de fer-li un vestit llarg i pagar-li la trementina, en atenció a la seva pobresa ${ }^{82}$.

El 26 de juny de 1752, el canonge Clariana comunicà al Capítol la defunció de Gerivet, entonador de la present Seu, el qual morí pobre i no es podia costejar la sepultura. El Capítol digué qué ell se'n faria càrrec, però que si Gerivet tenia algun bé, hauria de servir per a aquest menester ${ }^{83}$.

Anton UTGER. Dormitorer/Entonador. Als llibres de la Caritat, Albarans, 1739-1741, f. 117, encara surt com Dormitorer i a partir del de 1741-43, f. 116, com Entonador. El 10 de maig de 1748, exposà al Capítol que, degut a sa perllongada malaltia, necessitava d'alguna subvenció. El Capítol recomanà al Caritater i a l'Administrador de la Pia Almoina que s'informessin, pel que feia a la malaltia d'Utger ${ }^{84}$. El canonge Roig, el Caritater, pel que sembla, donà comptes al Capítol, el dia 13 de maig següent, d'allò que rebia Utger de la Caritat, això és, més de 250 lliures, sense comptar l'estipendi de la missa. El Capítol resolgué, en conseqüència, que, tan sols per una vegada, li donessin 10 lliures i 4 sous, de la Caritat ${ }^{85}$.

El 23 d'agost del mateix any 1748, Utger presentà nova petició al Capítol, acompanyada de fe de metge i de cirurgià, els quals deien que necessitava mudar d'aires. I hi feia constar també que, malgrat l'ajut rebut, per la resolució precedent, el suplicant estava sense medis i impedit de dir

\author{
77. SIV. 20,f. $108 v$. \\ 78. SIV. 20,f. $113 v$. \\ 79. SIV. 20,f. $116 \mathrm{v}$ \\ 80. SIV. 20,f. 137. \\ 81. SIV. 20,f. 137 v. \\ 82. SIV. 20,f. 163. \\ 83. SIV. $21, f .18$. \\ 84. SIV. $20, f .101 v$ \\ 85. SIV. 20,f. 102.
}


missa més de 22 mesos, per ses malalties, raó per la qual demanava presència, llicència i algun subsidi. El Capítol li concedí 14 lliures de subvenció, a més de les altres gràcies ${ }^{86}$.

El 6 de setembre de 1751, li concediren llicència per anar fora a fortificarse, en virtut de fe de metges i també presència i deu lliures de gràcia ${ }^{87}$. El 26 de juny de 1752 , sol-licità novament permís, per mudar d'aires, tot presentant sempre la consabuda fe de metges i demanà alguna subvenció, en atenció a sa pobresa. Fou resolt donar-li la llicència i la presència i que dels propis salaris, li avencessin tres o quatre mesos ${ }^{88}$.

L'acta capitular del 17 de novembre de 1752, ens parla ja del "quondam" entonador Utger. Això vol dir que ja habia mort, però no diu quin dia. Possiblement feia molt poc. La qüestió era que, durant la malaltia, li havien avançat uns diners i, a l'hora de l'òbit, era deutor de dues lliures, les quals i, si alguna cosa havia percebut de més, les hi condonava el Capítol ${ }^{89}$.

Joan BOIX, entonador, de Vic. El document que ara comentaré i algun altre més, sembla que parla d'un "Joan Doix", però donat que no n'ha sortit cap de Joan Doix, i sí un Lluís Boix i d'altres Boix, penso que Doix fou un mal entès de l'escribà o una grafia peculiar seva de la " $B$ " $i$ per aixó els interpreto, entenent-los de Joan Boix, el qual presentà fe de metge, el 20 de maig de 1750, per certificar la necessitat que tenia de mudar d'aires. El Capítol li concedí la llicència i la presència $^{90}$. El 4 de juny de 1751 , feia present al Capítol que, a més de la greu malaltia que patia, des de feia quatre anys, el prop passat 28 d'abril, li havia sobrevingut un nou accident, el qual li havia ocasionat moltes despeses en metges i medicines i demanava al Capítol alguna subvenció, el qual li digué que no tenia $\operatorname{lloc}^{91}$. Document decisiu, per a mi, de que es tracta de Joan Boix i no de Joan Doix, és el d'1 de març de 1752, on es fa un reajustament de les distribucions per tal d'estimular l'assistència a les hores $i$ allí és ben evident que es tracta de Joan Boix ${ }^{92}$.

Josep PRATS/ PRAT. Entonador/Dormitorer. El 28 de novembre de 1749, demanà que li donessin, o rosses, o més salari, en atenció als més de setze anys que servia al Capítol. Aquesta súplica fou lliurada al Protector de la Capella ${ }^{93}$.

El 27 d'agost de 1753, el Canonge Morera proposà, que, donat que el Cor quedava ben servit amb els entonadors que hi havia, i que, no essent de servei mn. Josep Prat, el qual, d'altra banda, tenia obligació de residir en l'església de Caldes, on tenia el seu títol, donava peu a insinuar-li, que el Capítol es donava per satisfet i que podria anar a cumplir en el lloc de la seva principal destinació. Es decidí tractar aquesta qüestió quan hi serien tots els Capitulars ${ }^{94}$.

Mateu?/MATEU? Possiblement, cal entendre que l'acta capitular del 23 d'agost de 1751, parla d'un Mateu entonador. Ara bé, donat que hi havia un Mateu BLANCH i un T. MATEU, resul-

86. SIV. 20,f. $117 v$.

87. SIV. 20,f. $275 v$.

88. SIV. $21, f .17 v$.

89. SIV. $21, f .52 v$.

90. SIV. $20, f .178$.

91. SIV. 20, f. 254.

92. SIV. $18, f .314 \mathrm{v}$

93. SIV. 20,f. $162 v$

94. SIV. $21, f .113$.

Anuario Musical, 56 (2001)

(c) Consejo Superior de Investigaciones Científicas Licencia Creative Commons 3.0 España (by-nc) 
ta difícil dir a quin dels dos es refereix el document, encara que pel costum de referir-se a les persones pel cognom, m'inclinaria pel segon. En tot cas, l'acta diu que els canonges comissionats per a la qüestió dels entonadors, proposaren que, aquest entonador, després de tant de temps com servia a la Catedral, no havia rebut cap gratificació i pensaven que la circumstància de cercar entonadors, aleshores, podria ser una bona oportunitat per donar-la-hi. Fou deixat a la discreció dels susdits comissionats ${ }^{95}$.

Joan GARRIGA. Entonador. El 31 de juliol de 1747, presentà una súplica, acompanyada de fe de metge, dient que necessitava, per al restabliment de la seva salut, restar el proper mes d'agost i part del setembre, en casa de sos Pares, en el lloc de Torà. El Capítol li concedí la llicèn$\mathrm{cia}^{96}$.

El canonge Morera féu relació, el 21 de juny de 1748, de les males maneres amb què mossèn Garriga, entonador, parlà del Mestre al mateix Protector i sense motiu. El Capítol manà al susdit Protector Morera que multés Garriga, tot privant-lo els dies que cregués convenient ${ }^{97}$.

El 13 de maig de 1750, donaren resposta a la petició de major conveniència feta per aquest entonador, perquè no podia mantenir la seva família, càrrega que li havia sobrevingut per haver mort el seu pare. Li digueren que no tenia $1 \operatorname{lloc}^{98}$. Potser degut a totes aquestes circumstàncies, trobem que Garriga, una setmana després, això és, el 20 de maig, demanava permís per passar a Resident, en la vila de Torà, bo i essent perpetuat en la Catedral i suplicà al Capítol que li manés tot el que fos del seu grat. El Capítol li respongué que es donava per ben servit"9

Miquel VENDRELL. Entonador. No em consta el moment del seu nomenament. La primera notícia que he trobat és que el canonge Marquet féu present, el dia 30 d'abril de 1753, que havia gastat 77 lliures, 15 sous i 5 diners en vestir i fer hàbits de Cor a aquest músic i reclamava el corresponent manament o justificant. Així mateix, digué que, perquè pogués aprendre més i estar millor custodiat, havien decidit els comissionats de posar-lo en casa del Mestre de Capella, donantli per la despesa sis sous diaris, amb l'obligació de rentar-li i apedassar-li la roba i que dita despesa havia començat el dia 1 de març del corrent $1753^{100}$.

El 4 d'octubre de 1754, li donaren llicència, presència i alguna subvenció per anar alguns dies fora ${ }^{101}$ i el 20 de desembre de 1754, el canonge Marquet proposà al Capítol, que aquest entonador demanava una caritat per subvenir la seva mare vídua, la qual havia estat molt malalta. El Capítol resolgué donar-li una dobla d'or i manà que s'afegís al compte del susdit entonador ${ }^{102}$.

Josep GOMIS/GOMES. El 14 de març de 1748, el canonge Clariana proposà al Capítol que hi havia

$$
\begin{aligned}
& \text { 95. SIV. } 20, f .272 . \\
& \text { 96. SIV. } 20, f .66 . \\
& \text { 97. SIV. } 20, f .108 v . \\
& \text { 98. SIV. } 20, f .177 v . \\
& \text { 99. SIV. } 20, f .178 . \\
& \text { 100. SIV. } 21, f .85 . \\
& \text { 101. SIV. } 22, f .42 . \\
& \text { 102. SIV. } 22, f .54 .
\end{aligned}
$$


"un Mosso nat.l de Lleyda anomenat Josep Gomis, lo qual te una veu singular de contrabaix i bastants principis de solfa",

tot el qual era un bon fonament per a esperar que amb la pràctica seria útil a la Catedral. Ara bé, li resultava impossible de mantenir-se i poder-se aplicar, per causa de la seva gran pobresa, detalls que confirmaren diferents capitulars, coneixedors de la veu del jove i de les altres circumstàncies esmentades. En atenció a tots aquests testimonis, el Capítol resolgué que els Protectors dels escolans i de la Caritat miressin com es podria mantenir i aplicar i, al mateix temps, l'autoritzaren perquè entrés al Cor amb hàbits, per ajudar els estonadors i practicar-se ${ }^{103}$.

La petició d'algun ajut econòmic i d'augment de sou serà el "leitmotiv" de les intervencions d'aquest i de tots els músics, en general, com s'ha pogut anar observant i es repetirà en endavant. La Catedral, de la seva banda, ho anava remeiant el millor que podia. Efectivament, el 26 de maig de 1752, trobant-se malalt, demanà alguna subvenció per fer-se algun remei. El Protector de la Capella fou l'encarregat de tenir-ne cura i remeiar-10 ${ }^{104} \mathrm{i}$ el 31 del mateix mes, davant de l'informe del susdit Protector, li renovaren la missió d'assignar al malalt la caritat que millor li semblés ${ }^{105}$. El 15 de gener de 1753, tornà a demanar alguna gratificació, per compensar-se de l'excessiu treball que havia tingut darrerament, en especial en les processons de rogatives per demanar la pluja. El Capítol ho cometé als Comissaris dels Entonadors del Cor ${ }^{106}$. I, el 14 de desembre de 1753, encara demanà algun ajut més anualment, per poder-se tractar amb major decència i es prengué l'acord de donar-li 50 lliures més cada any ${ }^{107}$.

T. MATEU. L'he al·ludit, en parlar del redreçament del Cor, quan el Capítol decidí donarli de fix a ell i a Gomis, cent vint lliures.

Donat que els documents quasi bé sempre es refereixen a les persones designant-les pel cognom, per això crec, que, l'acta que ara comentaré, es refereix a aquest entonador. Resulta que, el dia 27 de setembre de 1754, el canonge Bellet comunicà al Capítol, que mn. Mateu, entonador, havia obtingut dos dies de permís per anar fora i que, després, s-hi quedà uns dies més, per trobarse indispost. El Capítol li donà la presència de tot el temps que romangué fora ${ }^{108}$.

Sebastià SANZ, conegut també pel "Carabaca"/"Arabaca", nom del lloc d'on era originari, habitant, però, de Barcelona, exposà al Capítol, el dia 19 de setembre de 1749, que es trobava amb veu de contrabaix, i suplicava que li permetessin entrar en el Cor, per tal de probar sa veu, permís que el Capítol li concedí de bon grat ${ }^{109}$. El 28 del mateix setembre es fa menció d'ell com entonador i li assignaren 4 sous diaris, durant quatre mesos, els quals sous li pagaria el Caritater, qui també tindria cura de la seva aplicació i en faria relació al Capítol, al seu moment ${ }^{110}$.

103. SIV. 20,f. 93.

104. SIV. $21, f .9$.

105. SIV. $21, f .12$.

106. SIV. 21, f. 67.

107. SIV. 21,f. 126v.

108. SIV. 22, f. 40.

109. SIV. 20, f. $156 \mathrm{v}$

110. SIV. 20,f. 157 .

Anuario Musical, 56 (2001) 
El 19 de febrer de 1750, el canonge Roig exposà al Capítol que aquest músic, el qual tan sols havia cobrat els quatre sous diaris que li havien assignat, s'havia aplicat a l'estudi de cant pla i, segons l'informe del Mestre i de l'entonador, podria servir l'Església, si es practicava, cantant en el Cor. El Capítol acceptà que practiqués, durant sis o vuit mesos, donant-li més subvenció, segons el criteri del canonge Roig, per tal de poder formar millor judici sobre la seva aptitud per a entonador $^{111}$.

D'aquest entonador, es deia més amunt, el 19 de novembre 1751, que, tenint en compte que era inútil enterament, semblava bé expel-lir-lo, resolució que, pel que diré ara mateix, es degué dur a terme immediatament. En efecte, el 20 de desembre de 1751, Sebastià Sanz, altre dels entonadors, manifestà al Capítol que, trobant-se lluny de Toledo, son país, no se'n podia anar en el temps fort del fret i suplicava que el Capítol el mantingués, durant el temps més rigorós. El Capítol li ho concedí per a tot el el mes de gener, però desprès hauria de posar en execució la disposició dels comissionats, disposició que no em consta, si bé, a la nota marginal, es parla de $\operatorname{gr}[a c i]^{a}$ y despido ${ }^{112}$.

Mateu BLANCH. L'acta capitular del 17 de setembre de 1751, tot parlant d'aquest beneficiat de la Catedral, ens assabenta de més coses d'aspecte general, referides als entonadors. Ens diu, doncs, que Blanch, entonador interí, presentà una súplica, exposant que, el diaconal Campà, del qual era suplent, desconfiava que el Capítol donés al susdit Blanch el mateix que acostumava a donar als altres, en el qual cas, no podria tenir-lo més a casa seva i donar-li les despeses. Amb la súplica, doncs, demanava que el Capítol deliberés a favor seu. El Capítol resolgué que, mentre Blanch serviria l'ofici d'entonador, li donaria el mateix que donava als altres dos entonadors interins i també ordenà que, aquesta decisió, fos comunicada a mn. Campà, perquè no deixés de donarli els aliments. En conseqüència, sabem que, en aquests moments, al menys, hi havia tres entonadors interins ${ }^{113}$.

Possiblement li van cridar l'atenció, per manca de puntualitat i, en descàrrec, exposà al Capítol, el 12 de maig de 1752, que la dificultat que tenia per servir amb puntualitat el seu ofici d'entonador era deguda al fet que, essent beneficiat de St. Sever, aquesta Comunitat li donava vint intencions de missa cada mes, les quals havia de celebrar a quarts de dotze. D'altra banda, recordava que, en altra ocasió, el Capítol li digué que, quan seria ordenat de prevere, li donarien missa quotidiana a la Catedral i, com que ja estava ordenat, per això demanava aquesta intenció, per tal de poder servir amb més puntualitat totes les hores. El Capítol li respongué que no tenia lloc la súplica $^{114}$. El 9 de febrer de 1753, recordà al Capítol que encara no cobrava de l'Administració de St. Sever i, per això, demanava algun ajut al Capítol per vestir-se, petició que fou comesa als Comissionats dels Entonadors ${ }^{115}$, sense que consti del resultat.

El 4 de maig de 1753, demanà llicència per anar 18 dies a la seva pàtria -de la qual no es fa menció-, on li havien ofert l'admissió en l'església i resolgueren donar-li la llicència i tan sola-

111. SIV. 20,f. $168 v$.

112. SIV. 20, f. $290 v$.

113. SIV. 20, f. $277 v$

114. SIV. 21,f. $2 v$.

115. SIV. $21, f .72 v$. 
ment la presència del salari que percebia ${ }^{116}$. Per les notícies que encara trobem després, hom dedueix, que no tingué èxit la gestió.

Una petició de més salari, a més de la quantitat que rebia, per mantenir-se amb més decència, presentà al Capítol, el 10 de maig de 1754 i fou passada la comissió al canonge Protector dels escolans $^{117}$. El Capítol prengué resolució sobre aquesta súplica de Blanch, el dia 24 del mateix maig, decidint que li fossin donades 25 lliures de la Caritat, de moment, fins a tant cobrés de St. Sever ${ }^{118}$. Altra petició presentà el 14 d'abril de 1755 , demanant que, a més a més de les distribucions, li assignessin quelcom de més, per tal de poder anar satisfent els seus empenyoraments i fou resolt, que el Caritater li donés 25 lliures per una sola vegada ${ }^{119}$.

Tomàs RAVENALS/REVANALS/RAVANALS. Sembla que la referència que es fa a l'acta capitular del 24 de gener de 1752, a un músic, sense donar-ne, però, el nom, cal entendre-la d'aquest Tomàs, per les coincidències que s'observen en els altres documents que en parlen, d'ell, això és, era valencià i tenia molt bona veu. Efectivament, el sobre referit dia, el canonge Marquet, comissionat per cercar entonadors, llegí una carta d'un pretenent valencià, essent molt bona la fama que corria d'ell, però que no gosava venir, perquè no tenia qui li pagués el viatge. El Capítol prengué la precaució d'informar-se, a més a més, per un altre camí i decidí, que, si l'informe tornés a ser favorable, no hi hauria inconvenient en pagar-li el viatge ${ }^{120}$.

De fet, es trigà a resoldre's l'assumpte del músic valencià, ja que, fins al primer de setembre del mateix any, no se'n torna a parlar i, aleshores, els canonges comissionats en la qüestió dels entonadors per al govern i harmonia del Cor, proposaren que havia comparegut un tal Tomàs Ravenals, el qual, segons informes, era de conveniència, per ser destre de solfa i prou veu. El Capítol l'admeté com a entonador i deixà en mans dels comissionats que li fessin la conveniència per a la seva manutenció ${ }^{121}$. Les conveniències i la perpetuació que li concedí el Capítol, tres dies després d'admetre'l, això és, el 4 d'aquell mateix setembre, confirmen que l'informe que s'havia donat sobre la seva preparació musical i la seva veu havia estat favorable. En total li oferiren 300 lliures $^{122}$.

No obstant el bon acolliment que li donà el Capítol barceloní, hi féu una estada ben curta a la Catedral, ja que, el 29 de setembre de 1752, obtingué un mes de permís per anar a València a veure la seva mare, rebent tan solament el salari assignat, però no les distribucions ${ }^{123} \mathrm{i}$, a l'acta del 10 de novembre immediatament següent, es diu que, tot i havent estat perpetuat, escrigué dient que no tornaria més a servir en aquesta Catedral, per haver obtingut col·locació en una altra església. El Capítol resolgué que fos tingut com no perpetuat ${ }^{124}$.

116. SIV. 21, f. 86v.

117. SIV. 22, f. 3 .

118. SIV. $22, f .5 v$

119. SIV. 22, f. 70v.

120. SIV. 20 ,f. 297 v

121. SIV. 21, f. 35v.

122. SIV. 21, f. $36 v$.

123. SIV. 21,f. $40 v$.

124. SIV. $21, f .50$. 
N. N. El canonges comissionats per al redreçament del Cor comunicaren al Capítol, el 5 de febrer de 1753, que havien trobat un mosso amb una bona disposició per a entonador i pràtic de solfa i que, cas que el Capítol decidís admetre'l, li assignés també una conveniència. El Capítol l'admeté i deixà al bon fer dels comissionats l'establir la conveniència. Lamento no poder-lo identificar, car els documents consultats tampoc no ho fan ${ }^{125}$.

Anton MONLLEÓ, membre destacat de la Capella de Música, com es dirà més avant, per la seva veu de contrabaix i la seva habilitat, demanà al Capítol, el dia 27 d'agost de 1753, en atenció al llarg servei prestat a la susdita Capella, que l'admetés com a entonador, amb la conveniència que li semblés millor. El Capítol l'admeté, realment, però l'establiment de la conveniència la deixà a mans del Protector dels escolans ${ }^{126}$.

El 24 de setembre de 1753, el Succentor Vilar, juntament amb els altres comissionats d'entonadors per a la bona harmonia del Cor, es referí a l'admissió d'aquest pretenent, el 27 d'agost prop passat, al qual, per la seva veu i habilitat, el consideraven digne de la conveniència de 300 lliures anuals, comprés en elles el salari, les distribucions, la part de la Capella i altres guanys que li poguessin correspondre, sense entrar-hi les franquícies i l'indivís, proposta que fou $\operatorname{acceptada}^{127}$.

Pere Anton N. Altre exponent de la preparació dels músics de la nostra Catedral de Barcelona, pel fet d'estar preparat per servir un magisteri de música. En efecte, l'acta capitular del 13 de maig de 1754 diu que aquest entonador, amb permís del Capítol anà a oposar-se al magisteri de Figueres i, quan tornà, el Capítol resolgué donar-li totes les distribucions del temps, en què estigué fora $^{128}$.

Josep PRESAS. El 10 de novembre de 1741, el succentor Vilar i els canonges Roldós, Barata, i Nadal, comunicaren al Capítol que, havent seguit la comissió que tenien, havien analitzat les pretensions, entre d'altres músics de la Capella, la de Josep Presas, i havien conclòs que caldria

“contentar... al segon [Josep Presas] ab 60 lliures de salari... Respecte al segon, se ha resolt en tot, com han proposat, y discorregut los S.ors Com.ris ${ }^{129}$.

El 20 de juny de 1755, feia presents els seus mèrits per demanar augment de salari, petició que fou comesa al Protector de la Capella ${ }^{130}$. Aquest tornà la resposta, el 3 de juliol immediatament següent i era partidari que li augmentessin quelcom. El Capítol, en consequiència, decidí augmentar a Presas 15 lliures anuals de salari ${ }^{131}$.

\author{
125. SIV. 21,f. 72 . \\ 126. SIV. 21, f. $112 v$. \\ 127. SIV. $21, f .116$ \\ 128. SIV. 22, f. 5. \\ 129. SIV. $18, f .289 v$. \\ 130. SIV. 22, f. $85 v$. \\ 131. SIV. $22, f .88$.
}




\section{Contralts. Noms i notícies}

Qüestions generals. En els apartats anteriors, he parlat de diferents elements de la Capella de Música de la Catedral, entre els quals cal destacar les veus blanques, representades pels mynons de cota de grana, dels tenors, representats principalment pels Diaconal i Subdiaconal, pels contrabaixos -i devien ser els baixos-, els quals trobem més sovint entre els entonadors $i$, ara, considerarem els contralts, corda que devia contemplar principalment cantors adults.

N. N. El 10 de gener de 1749, el canonge Morera féu present que hi havia un músic, veu de contralt, el qual pretenia servir al M. I. Capítol. Fou resolt que d'això se'n tractaria en un altre capíto $^{132}$, com efectivament succeí, el 13 de gener immediatament següent, amb la subsegüent admissió del pretenent i amb l'encàrrec al susdit canonge Morera d'estudiar quina conveniència li podrien fer ${ }^{133}$. Aquesta darrera acta, referida a aquest contralt, no ens dóna el nom, però sí la procedència del personatge. Diu que era de Balaguer i es pensà en confiar-li el contrabaix i la viola, per no haver-hi ningú, aleshores, que els toqués, cosa que diu molt a favor d'aquest pretenent. Fou resolt que, pel fet d'ésser ja admès, li fos feta la corresponent conveniència, consistent en 40 lliures anuals, les quals les hi donaria el Caritater i l'Administrador de la Pia Almoina, una rossa. De la resta, però, se'n tractaria en un altre capítol ${ }^{134}$.

Bernat CASADEMUNT. Músic contralt de la Capella. El 8 d'octubre de 1751, feia present la "indecencia" del seu vestit, fins al punt que s'avergonyia d' anar amb la Capella, degut a la falta de medis i al fet que tenia molta família, raons per les quals demanava alguna remuneració. Aquesta súplica fou comesa al Protector de la Capella ${ }^{135}$.

Joan FELIU. Joan Feliu, contralt i músic "antiquior" de la Capella de la present església, exposà al Capítol, el 17 de gener de 1749, que el Mestre pretenia expoliar-lo de les primeres siestes, les quals li corresponien. Per aconseguir-ho, el Mestre havia "commogut" altres músics que ho desitjaven i demanant al senyor Protector que li prohibís assistir-hi, com en efecte, havia succeït el dia anterior i ell, tot obeïnt, no hi assistí, per no provocar qüestions. Tanmateix, suplicava al Capítol que es dignés atendre'l i manés que fos respectada l'antiga i justa possessió. El Capítol demanà al Protector que posés en pràctica l'estil de la Catedral i que ho arreglés amb el Mestre per a consol del suplicant ${ }^{136}$.

El 23 de maig de 1749, Feliu, ja jubilat de la Capella de Música, demanà augment de salari, en compensació del que li faltà de les siestes i misses matinals, petició que fou comesa al Protector de la música ${ }^{137}$.

El 9 de novembre de 1753, aquest contralt es queixà al Capítol que, després de quaranta anys que servia la Capella de Música, en feia quatre que li faltaven trenta lliures per la meitat de

132. SIV. 20,f. $128 v$.

133. SIV. 20, f. 128.

134. SIV. $20, f .134 v$

135. SIV. 20, f. $280 v$

136. SIV. 20,f. $129 v$.

137. SIV. $20, f .142$. 
les siestes i vint lliures més de les misses matinals. Es cometé la queixa als canonges comissionats per al redreçament de la susdita Capella de Música ${ }^{138}$. El 26 següent, li respongueren que la seva queixa no tenia $1 \operatorname{loc}^{139}$.

Anton MAJORAL. Contralt. El 2 de març de 1752, presentà una súplica al Capítol, en la qual manifestava que, amb les 40 lliures, el pa de rossa, la part de la Capella i la meitat de les misses matinals, no tenia prou per al sosteniment de la família, raó per la qual demanava al Capítol que es dignés assenyalar-li l'altra meitat d'advencions i siestes de la Capella, mantenint-li íntegres els primers salaris. La súplica fou comesa al Protector de la Capella ${ }^{140}$.

El 14 de juliol de 1752, el contralt Anton Majoral, donat que no li abastava per viure el salari que tenia a la Catedral, demanà al Capítol permís per a anar-se'n a casa seva i alguna subvenció i gratificació pels seus serveis. El Capítol delegà en el canonge Alòs, perquè li donés la gratificació que li semblés més convenient ${ }^{141}$. Alòs, en la sessió capitular del 19 del mateix juliol, proposà que li podrien donar 14 lliures de gratificació, la qual quantitat fou acceptada i la carregaren contra la Caritat $^{142}$.

Francesc SALT i SALLENT/SELLENT. El Mestre de Capella demanà al Capítol, l'11 de setembre de 1752, fins i tot amb un matís d'exigència, que manés que Francesc Salt i Sellent, clergue, fos admés a la Capella de Música, proposta que fou deixada en mans del Protector dels escolans ${ }^{143}$. Aquest, per la seva banda i en la sessió capitular del 15 dels susdits mes i any, es referí a la súplica precedent del Mestre de Capella, la qual li havia estat comesa l'11 del corrent i afegí que hi havia d'altres músics, els quals també desitjaven donar la seva súplica. Fou resolt que s'admetés la súplica i que s'ajornés l'elecció de contralt ${ }^{144}$. Probablement, els músics, o alguns músics de la Capella opinaven en contra del Mestre i del músic que proposava, això és, de Francesc Salt i presentaren un Memorial, del que no tinc cap més notícia que la de l'acta capitular del 22 de setembre del susdit any 1752, a la qual hom pot llegir que el Capítol resolgué admetre l'esmentat Salt com a tenor-l'elecció era per a contralt-i menysprear el Memorial per atrevit, de poc respecte, y es digne de castich. En conseqüència, determinaren que s'esbrinaria quins havien estat els qui l'havien presentat i serien castigats de la manera que semblaria al Capítol"145.

Manuel SALA, contralt, demanà, el 31 de gener de 1755, els mateixos guanys que obtenia el seu antecessor Anton Majoral, però d'una manera especial, el salari que pujava fins a 55 lliures, petició que fou comesa al Protector de la Capella ${ }^{146}$. La resposta a la present petició fou donada el 3 de febrer següent, amb aquest detall: que, a l'acta capitular, a la qual s'al·ludeix a l'an-

\footnotetext{
138. SIV. 21, f. 122.

139. SIV. $21, f .125$.

140. SIV. $20, f .304$ v

141. SIV. $21, f .24$.

142. SIV. $21, f .26 v$

143. SIV. $21, f .37 v$

144. SIV. 21, f. 38v

145. SIV. 21, f. 39.

146. SIV. 22, f. 60 .
} 
terior, hom llegeix que es tractava d'una "Sup.ca de Planàs", en lloc de "Sala", no sé si per error de l'escrivà, o perquè, com en el cas de l'arpista Sala, el qual tractaré més avant, era conegut per ambdós cognoms. El que sí que és cert, és que, per l'al·lusió a la súplica del 31 de gener, aquesta la feia Manuel Sala ${ }^{147}$. No és improbable, d'altra banda, que aquest Manuel Sala fos la mateixa persona que el Manuel Planes/Planas, ja que aquest, l'any 1752, passà de contrabaixista a contralt, com diré més endavant. Aleshores seria més comprensible, com en altres casos analitzats en aquest mateix treball, que la súplica precedent fos, adés de Sala, adés de Planàs, però la mateixa persona.

Tenor

Ramon PRATS. L'acta de la seva admissió, 16 de maig de 1731, com consta en altra publicació meva (Tonos de Francesc Valls... i Vol. II, en imprempta), diu que l'admitien per a Subdiaconal i que tenia veu de contralt (SIV. 16, f. 69). El canonge Morera féu relació, el 21 de juny de 1748, del comportament insubordinat de Ramon Prats, tercer tenor de la Capella i paraules injurioses al Mestre de Capella, a l'altar major, en una de les tardas de l'octava de Corpus. El Capítol considerà que el referit motiu i altres circumstàncies el feien indigne de sufrir-lo en l'església i, per tant, ordenà que el susdit Protector l'acomiadés ${ }^{148}$.

El 27 de setembre de 1748, presentà una súplica acompanyada de fe de metge, amb què demanava llicència per anar fora i presència. El Capítol li ho concedí tot i, a més, intenció de $\operatorname{missa}^{149}$.

El 8 de novembre del susdit 1748, demanà perdó al Capítol i la reintegració en son ofici de tenor. El Capítol remeté la petició al Vicari General ${ }^{150}$. L'acord capitular prés el 22 del mateix novembre, diu que es resolgué donar-li una quantitat no expressada, per tal que pogués tenir conveniència en altra part i que quedés acomiadat definitivament de la Capella de música ${ }^{151}$.

\section{Instruments}

\section{Orgues i organista}

Pel que fa als orgues, tan sols trobem una notícia, sense massa relleu, referida a l'orgue de Sta. Eulàlia. En canvi, tocant a l'organista, es produí el nomenament d'un organista auxiliar i la consegüent successió, després de l'òbit del titular. Quant als instruments, els ordenaré alfabèticament.

147. SIV. 22, f. $68 v$.

148. SIV. 20,f. $108 v$.

149. SIV. 20, f. 120.

150. SIV. 20, f. 123 .

151. SIV. 20,f. 126 
Orgue de Sta. Eulàlia. El 19 de maig de 1749, l'organer Josep Boscà ${ }^{152}$, manifestà al Capítol que l'organet de Sta. Eulàlia havia caigut i calia restaurar-lo. El Capítol decidí que s'adobés i passà la súplica al canonge Mateu ${ }^{153}$. El 25 de juny, l'organet ja estava compost i Boscà reclamà al Capítol les 8 lliures que importava el treball de netejar i compondre el susdit instrument $^{154}$.

Joan SALÓ. El 17 de febrer de 1747, fou convocat un Parlament en la sagristia pel canonge Esteve Bellet, qui el presidí i proposà que l'organista jubilat Joan Saló havia demanat al Capítol que li administrés el Viàtic, ja que es trobava malalt greu. Es resolgué que li seria administrat, després de completes ${ }^{155}$. Tanmateix, l'òbit de Saló no es produí fins al 26 de maig de 1747, com explico a la meva tesi doctoral (pg. 166).

Francesc MARINER, organista interí, tot seguit de la mort de Saló, això és, el 29 de maig de 1747, suplicà al Capítol que, havent mort Joan Saló, l'organista principal, l'anomenessin a ell al seu lloc. El Capítol, doncs, resolgué nomenar-lo principal, amb tots els emoluments i honors de dit ofici d'organista, del qual acte en prengué nota el notari capitular ${ }^{156}$.

El 28 de juny de 1748, manifestà al Capítol els desigs que tenia d'ordenar-se de sacerdot, però com que no disposava de cap altre recurs, sinó la pietat del Capítol, li demanava que el volgués perpetuar en l'ofici que servia d'organista. El Capítol accedí a perpetuar-lo tan sols en aquella part de rèdits que arribés a còngrua (no consta quina era, aquesta còngrua) i fins a tant obtingués algun títol eclesiàstic que produís la còngrua necessària (la qual tampoc no consta). ${ }^{157}$.

\section{Organer}

Josep BOSCÀ, difunt. El 14 de gener de 1752, Rosa Boscà, vídua de Josep Boscà, mestre d'orgues, i Anton Boscà i Josep Boscà, germans del difunt, tots mestres d'orgues, demanaven, cadascú del seu indret, l'adjudicació d'aquest ofici de mestre d'orgues de la present església Catedral, peticions que foren comeses als Obrers majors ${ }^{158}$. Arribats en aquest punt, crida l'atenció el fet, que, segons el present document, hi hauria hagut dos germans Boscà anomenats Josep, cosa que, quan ocorregué la successió del seu pare no es féu constar ${ }^{159}$. No diré que ho trobo impossible, però sí molt estrany, ja que no se l'anomena abans. Realment, no sé què dir d'aquest tercer Josep -en relació amb el pare-, sinó que el document ho fa constar així.

152. La major part dels documents d'aquest període referits als organers Boscà, escriuen "Buscà", que per coherència amb els documents de les publicacions anteriors, normalitzo en "Boscà", tot atribuïnt a una transcripció fonètica de la "o" closa, la conversió d'aquesta en "u".

153. SIV. 20, f. 141 .

154. SIV. $20, f .146$.

155. SIV. $20, f .43$.

156. SIV. 20, f. 57 v.

157. SIV. 20, f. 110.

158. SIV. 20,f. 295. Barcelona, 1980.

159. Pavia Simó, J., "Historia del órgano mayor de la Catedral de Barcelona”, CSIC, AnM, 1978-1980, pp. 81-130, 
Anton BOSCÀ. El 4 de febrer de 1752, el canonge Quintana féu relació del Pretensor de l'orgue, però, degut probablement a la dificultat que hi devia haver, es convidà a capítol per al dilluns vinent ${ }^{160}$, dia 7 de febrer, en el qual fou elegit Mestre d'orgues, per escrutini, Anton Boscà, amb els salaris i emoluments acostumats. De tot el qual en llevà acta el notari capitular ${ }^{161}$.

\section{Manxaire}

Feliu ROS. E1 28 de maig de 1749, el feren propietari cellerer, manxaire i llantier, com ho havia estat ja el seu pare. El notari en llevà acta ${ }^{162}$.

\section{Arpa, arpista i clarí}

Francesc RUEDA. El 14 de juliol de 1747, va demanar que el fessin oficial i que, donat que, al present, era segon arpista i clarí, tot alhora, demanà també tota la part de la Capella. El Capítol li ho concedí tot, amb les preheminències i franquícies que tenien els demés, en semblants ofi$\operatorname{cis}^{163}$.

Joan ROSSELL. Arpista. L'1 d'agost de 1749, demanà la gràcia de residir ${ }^{164}$ amb hàbits i tenir les distribucions, com ho tenia Campà, ja que la part de la Capella s'havia minorat i només tenia 20 lliures de salari i rosses (no diu quantes). Aquesta súplica fou comesa al Protector de la Capella $^{165}$. El dilluns 18 d'agost de 1749 , es donà la resolució a la súplica precedent de Rossell, sobre els hàbits i distribucions. El Capítol cregué que no tenia $1 l o c^{166}$.

\section{Arxillaüt}

Josep TORRABLANCA/TORREBLANCA. El 14 de juny de 1747, demanà una rossa més cada any, per poder-se mantenir amb decència, la qual rossa li fou concedida ${ }^{167}$

El 26 d'abril de 1752, en capítol extraordinari, convocat al temps de les lletanies, el Vicari General Vilar, manifestà que l'arxillautista Torrablanca es trobava molt greu i que per indicació dels metges s'havia de sacramentar per viàtic, sagrament que el propi malalt havia demanat. Es prengué l'acord de portar-li el viàtic, després de l'ofici ${ }^{168}$. La petició de la vacant d'arxillautista, ocasionada per la defunció de Torrablanca, feta, dos dies després de donar-li el viàtic, per Manuel Planas (v. aquest músic cantor), dóna a entendre que l'òbit es produí, el mateix dia que el viaticaren.

160. SIV. 20,f. 299.

161. SIV. 20,f. 300 .

162. SIV. 20,f. 143.

163. SIV. $20, f .64$.

164. En realitat, aquest mot, al ms., és quasi bé indesxifrable, per haver estat rectificat a sobre i, tot així, la frase és obscura. Diu "demana la Residencia dels habits".

165. SIV. 20,f. 151.

166. SIV. 20, f. $152 v$.

167. SIV. $59 v$.

168. SIV. 20, f. 316 v. 
Manuel PLANES/PLANAS, músic de la Capella, tot desitjant aprendre de contrabaix, suplicà al Capítol, el 19 de gener de 1750, que li deixessin l'esmentat instrument que es guardava a casa del Mestre, prometent que en tindria la màxima cura possible. El Capítol accedí a la petició, però a condició, que fos sempre sota el control del Protector de la Capella ${ }^{169}$. El 30 d'octubre del mateix any, manifestà al Capítol que ja es trobava hàbil per tocar el contrabaix i demanava tot alhora, la conveniència o salari que es donava a Jordi Marquès, súplica que el Capítol cometé al Protector de la Capella ${ }^{170}$. El 23 de novembre es deixà aquesta conveniència en mans del canonge Marquet $^{171}$, la qual degué tenir èxit, perquè el Nadal del 1750 , consta que ja cobrà com a tal ${ }^{172}$.

El 28 d'abril de 1752, en ocasió d'haver finit l'arxillautista Torrablanca (v. al seu lloc), sol-licitava aquesta vacant de primer arxillautista, tot confiant que, tenint en compte el molt temps que servia la Capella, esperava ser anomenat per a aquest ofici. El Capítol cometé la súplica al Protector dels Escolans. No li donaren aquesta plaça, però, el 19 de juliol de 1752, el canonge Alòs, proposà al Capítol que a Planas li podrien assignar l'ofici de contralt que tenia Majoral i que es donés com vacant el de Planas ${ }^{173}$, permuta que fou acceptada i es dugué a terme el mateix dia ${ }^{174}$.

El 18 d'abril de 1755, demanà mudar d'ayres, tot acompanyant la seva súplica d'un certificat de metge i també la presència de tots els guanys que li correspondrien de la Capella, petició que fou comesa al Protector, s'entén de la Capella, recomanant-li que procedís segons l'estil ${ }^{175}$.

Josep ROAIX, músic que m'era desconegut fins ara, dins de la Capella de Música de la Catedral, però els documents donen el seu nom i cognom, tal com els he transcrit. També demanà, el dia 28 d'abril de 1752, com Manuel Planas, la vacant d'arxillautista produïda per l'òbit de Torrablanca $^{176}$.

Francesc SALA i Francesc ROSSELL i SALA. No seria gens d'estrany que es tractés d'una mateixa persona i que el nomenessin Sala directament, per diferenciar-lo dels altres Rossell. I, per si pot afavorir aquesta hipòtesi d'identitat, als llibres de la Caritat, Albarans, 1751-1753, f. 131v, hom llegeix: Datas de Francisco Rossell arxilleutista i signa Francisco Rossell i Sala/Rossell i al llibre de la mateixa sèrie, anys 1753-1755, f. 128, diu: Datas de Francisco Rossell Arxilleutista i signa: Rossell. Ara bé, de la comparació d'aquestes rúbriques, hom dedueix que es deuen a la mateixa mà $i$, en consequiència, es tracta d'una mateixa i sola persona.

També demanava al Capítol que li assignés la vacant d'arxillaüt, data 5 de maig de $1752^{177}$. Però no la pretenia ell sol, la plaça, sinó que n'hi havia més, segons la relació que féu el Protector dels Escolans, el 12 de maig de 1752, de les súpliques a ell comeses i acordaren proveir la vacant

169. SIV. 20,f. 166.

170. SIV. 20,f. 210v.

171. SIV. 20, f. 216.

172. Caritat. Albarans, $1749-1751, f .117 v$

173. SIV. $21, f .26 v$.

174. Caritat. Albarans, 1751-1753, f. 120.

175. SIV. 22, f. $71 v$.

176. SIV. 20,f. 317 .

177. SIV. 21,f. 2. 
en el capítol següent ${ }^{178}$, de la qual provisió no en tinc constància. Tanmateix, sembla que la hi donaren a ell, ja que, Francesc Sala, arxillautista, l'1 d'abril de 1754, demanava augment de salari, convençut que li prometeren, quan va entrar ${ }^{179}$, a la qual petició donà resposta el Capítol, el 29 d'abril, amb la concessió d'una rossa, pagadora en diners ${ }^{180}$.

\section{Baixó}

Joan CAPÓ, capellaniu i oficial de la Capella demanà, el 12 de gener de 1750, que el perpetuessin, per tal de poder-se ordenar d'ordes majors, petició que li concediren, tot mantenint-li, també, els honors i emoluments que fruïa ${ }^{181}$. Cobrà de la Caritat, fins a l'any $1751^{182}$.

Josep CAPÓ, cobrà de l'Administració de la Caritat, fins a l'any $1751^{183}$.

Obò̀

Marià CORTÈS. Oboista de la Capella. Indirectament, sabem del seu traspàs, per la petició que féu l'oboista Fontrodona, l'1 de setembre de 1752, del salari que tenia Cortès, haven passat aquell â major vida ${ }^{184}$.

Tomàs ROSSELL. Encara que l'acta capitular del 22 de setembre de 1749, no doni el nom de l'oboista, ja que només diu que N. Rossell demanava la plaça de primer oboista ${ }^{185}$, crec que cal identificar-lo amb el Tomàs Rossell que signa rebuts com a tal ${ }^{186}$, puig que no apareix cap altre Rossell contemporani seu que toqués aquest instrument. Cal dir que amb ell n'eren tres els pretenents a la plaça d'oboè, això és, ell, Ciurach i Fontrodona, com consta tot seguit.

Francesc FONRODONA/FONTRODONA. El 19 de setembre de 1749, adduïa, com a mèrit, perquè li adjudiquessin la plaça d'oboè, vacant per òbit de Joan Pradell, el qual, a més a més, havia estat el seu mestre, el fet que havia estat escolà de grana i que feia ja més de set anys que servia la Catedral. El Capítol ho deixà en mans del Protector de la Capella ${ }^{187}$.

Sense cap mena de dubte, cal entendre referida a aquest músic l'acta capitular del 22 de setembre de 1749, on es diu que un tal N. Rossell demanava ser l'oboè primer de la Capella, petició que el Capítol confià al Protector de la Capella. Amb ell n'eren tres els pretenents a la plaça d'oboè, això és, ell, Ciurach i Fontrodona, com consta en altres apartats del present treball ${ }^{188}$. I d'a-

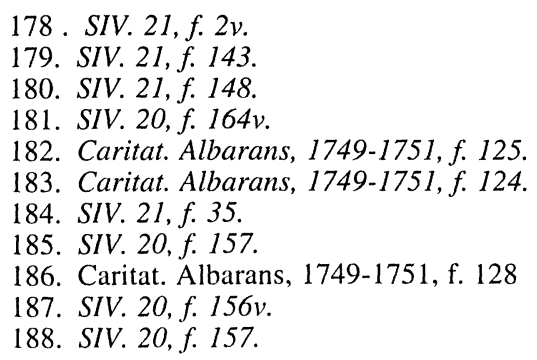

Anuario Musical, 56 (2001) 
quest assumpte no apareix cap altra notícia fins al primer d'abril de 1751, en què el canonge Marquet proposà al Capítol que seria bo anomenar Fontrodona oficial, en condició d'oboè segon, decisió que prengué el Capítol, en atenció al fet que Fontrodona havia entrat en lloc d'altre. El notari en llevà acta ${ }^{189}$.

L'1 de setembre de 1752, demanava el salari que rebia el difunt Marià Cortès, súplica que fou comesa al Protector dels escolans ${ }^{190}$. El 4 de setembre de 1752, el Capítol resolgué donar-li el salari que havia demanat ${ }^{191}$.

Joan CIURACH/SIURACH. Sembla que es tracta de l'oboista que entrà l'any 1735 i se n'anà el 1736, deixant la Capella ab poch lluim.t, com dic a l'altre treball sobre els Tonos de Valls, el qual està en imprempta. En tot cas, si és ell, degué tornar i, com ell mateix farà constar de seguida, actuava com a suplent de Joan Pradell. Efectivament, el 19 de setembre de 1749, el mateix dia que Fontrodona, presentà una súplica al Capítol, reclamant també la plaça d'oboè, vacant per òbit de Joan Pradell, la qual ell havia servit com a suplent, en la malaltia d'aquell. El Capítol també cometé la súplica al Protector de la Capella ${ }^{192}$. Pel que diré de seguida, sembla que la hi donaren. En efecte, el 13 de juliol de 1750, demanà al Capítol alguna part del salari que fruïa el seu antecessor, petició que fou comesa al Protector de la Capella ${ }^{193}$, i el 23 de juny de 1751, el canonge Marquet féu present una súplica de Ciurach, oboè primer, amb què demanava més salari, ja que estava carregat de família i li havia sortit altra conveniència millor. El Capítol deixà en mans del susdit canonge l'augment de salari del suplicant ${ }^{194}$. A més, un rebut seu de l'any 1750 , confirma que ja cobrava de la Caritat ${ }^{195}$.

La notícia que ara comentaré, fa pensar una vegada més en el nivell musical dels músics de la Catedral i, en aquest cas, de Ciurach. Efectivament, aquest músic, degut a la molta família que tenia, havia d'ajudar-se amb altres dedicacions, per ser-li insuficient el salari que guanyava. Aleshores, demanà permís al Capítol, el 10 d'abril de 1752, per anar a tocar amb l'orquestra de l'òpera d'aquesta Ciutat de Barcelona i el Capítol li respongué que deixés d'anar-hi, de moment $^{196}$.

El 13 de maig de 1754, demanà al Capítol que, puix son fill servia la Capella des de feia dos anys -primera i única notícia que tinc-, tocant el violí i cantant de contralt segon, el volgués admetre a la Capella, amb els mateixos càrrecs i obligacions, petició que fou tramesa al Protector dels escolans ${ }^{197}$, el qual informà el Capítol i, aquest, el dia 17 de maig, respongué que no tenia $11 \mathrm{loc}^{198}$.

189. SIV. 20, f. $241 v$.

190. SIV. $21, f .35$.

191. SIV. $21, f .36$.

192. SIV. $20, f .156 \mathrm{v}$

193. SIV. 20, f. $193 \mathrm{v}$

194. SIV. 20, f. 259v.

195. Caritat. Albarans, f. $127 v$.

196. SIV. 20, f. 311 .

197. SIV. $22, f .3 v$.

198. SIV. $22, f .4 v$. 


\section{Trompes}

Josep DRUMENT. Trompa. El 9 de setembre de 1754, Teresa Drument, esposa de Josep Drument, oficial de la Capella, amb 14 anys de servei, sol-licità una caritat diària per a subvenir son marit dement i alimentar sis fills, el major dels quals no arribava a 10 anys. El Capítol resolgué donar-li tres sous diaris, fins a la convalescència del seu marit ${ }^{199}$.

Pel que fa a la concessió anterior dels 3 sous diaris a Drument, per la seva malaltia, el canonge Bessa la recordà al Capítol, el 14 d'abril de 1755, ja que Drument no s'havia recuperat encara i el dubte era, si li havien de donar els tres sous des del 9 de setembre i si se li havien de continuar donant, en endavant. S'acordà donar-los-hi d'aleshores en endavant i es deixà a la discreció de l'esmentat Bessa i del Caritater, si li donarien, des del 9 de setembre ${ }^{200}$.

Joan Miserachs, trompa, el 5 d'abril de 1753, demanà llicència per anar a la Cort de Madrid, acompanyant alguns músics per a la Capella de Música de l'Exm. Sr. Duc d'Ossuna, però assegurà que deixaria un substitut al seu lloc, en servei de la Capella de la Catedral, llicència que li fou concedida ${ }^{201}$.

\section{Viola}

Josep SOLER fou anomenat per a la segona viola i oficial de la Capella de la Catedral, el 20 de març de $1749^{202}$.

\section{Violí}

Lluís MARTÍ. Violinista ${ }^{203}$. El 22 de gener de 1748, aquest músic -i gran copista de música- presentà una súplica al Capítol, tot manifestant que el Mestre i demés músics l'havien destituït de Procurador de la Capella, sense al·legar cap motiu i després d'haver portat la susdita procura durant 24 anys. La súplica fou comesa al Protector dels escolans ${ }^{204}$ i la resposta del Capítol, no es féu d'esperar. En efecte, el dia 9 de febrer del mateix any, el canonge Tagell digué que, tant la nova procura feta per la Capella de Música i la revocació de la que ostentava Ll. Martí, havien estat fetes precipitadament i sense convidar tots els vocals de la Capella i que el propi Mestre, cridat per ell diferents vegades, sempre havia respost amb poca atenció. El Capítol manà al president que donés

"al Mestre la deguda reprehencio, en attencio de ser nulla la resolució presa p.r la Capella lo dia 6 del corrent, y q.e se torne juntar la Capella, pera fer nominació de procurad. ${ }^{205}$.

199. SIV. 22, f. $36 \mathrm{v}$.

200. SIV. 22, f. $70 v$.

201. SIV. $21, f .80 v$.

202. SIV. 20, f. 135.

203. Caritat. Albarans, 1751-1753, f. 123.

204. SIV. 20, f. $86 v$.

205. SIV. 20, f. $88 v$. 
El dilluns 27 d'abril de 1750, resolgueren donar-li 10 lliures cada any de caritat, pels serveis que havia prestat a la Seu i per haver servit també la Capella de música ${ }^{206}$. Diferents rebuts dels Llibres de l'Obra, acrediten que cobrà per escriure, per ex., diferents himnes que mancaven als Salteris nous i els himnes per al Cor i per paper imperial, data 12 d'abril de $1751^{207}$.

Gabriel TERRI, Gabriel Terri, pvre. i violinista, féu present al Capítol, el dia 8 de novembre de 1748 , que, donat que, a més a més del seu deure, servia també la plaça de tenor que tenia Ramon Prats, era mereixedor de les distribucions que es donaven a aquest. El Capítol resolgué que no tenia lloc la peticióo ${ }^{208}$. El 28 d'abril de 1749 , les tornà a reclamar, adduïnt que ell el suplia en les seves malalties i absències i el Capítol li respongué igualment que la petició no tenia $11 \mathrm{loc}^{209}$.

Joan BUSQUETS, altre músic violinista destacat de la Capella de música de la Catedral de Barcelona, el qual va aconseguir entrar en la Capella de l'Encarnació de Madrid. S'acomiadà del Capítol de la Seu de Barcelona, el dia 12 de març de 1750, donant-li gràcies dels favors que li havia dispensat $^{210}$.

Joan BAYONA, músic de violí, demanà al Capítol, l'11 de març de 1751, que l'anomenessin oficial, per tal de tenir les franquícies. Fou comès al Protector dels Escolans ${ }^{211}$.

Carles TEIXIDÓ. Es tracta de l'escolà de grana que apareix más amunt, el qual en fou pels anys quaranta, i ara el trobem com a violinista, a l'acta capitular del 20 de novembre de 1752, presentant una súplica, de la qual no s'expressa el contingut i a la que el Capítol respon que no tenia $1 \operatorname{loc}^{212}$. Aquest músic confirma l'experiència que tenim tan repetida d'escolans que, un cop acabada la veu de tiple, resten com a músics a la mateixa Capella de la Catedral.

Altra súplica de Teixidó al Capítol, demanant el mateix salari que abans tenia Josep Capó, es troba a l'acta capitular del 10 de maig de 1754, tot fent present els seus serveis a la Capella, com a violinista i, el 13 de maig, fou resolt, que li donarien 10 lliures cada any, de l'Administració de la Caritat $^{213}$.

Josep CAPÓ, músic de la Capella, violinista. El 17 de desembre de 1751, Mariàngela Capó, vídua de Josep Capó, demanà una almoina al Capítol, el qual li concedí set lliures ${ }^{214}$.

Josep CAPÓ, fill de l'anterior, prevere i oficial violinista de la Capella de Música, amb motiu del nomenament de Terri per a Subdiaconal, demanà al Capítol, el 18 de febrer de 1754, que l'anomenés primer violí, càrrec que deixava l'esmentat Terri. El Capítol ho deixà en mans del Pro-

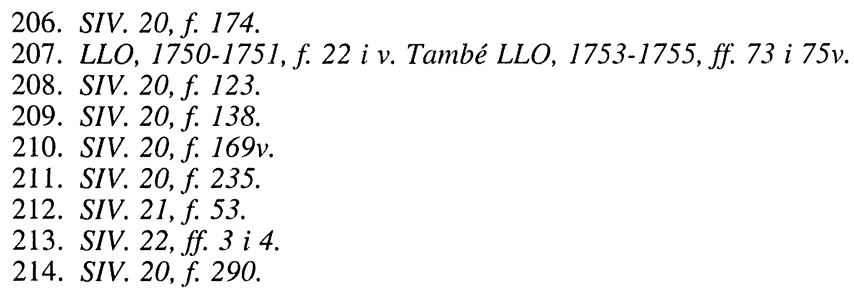


tector dels escolans ${ }^{215}$ i d'acord amb l'informe que aquest degué donar, el Capítol li concedí la petició, el 21 de març immediatament següent, amb el salari, però, que es donà a Terri, quan entrà a servir aquest ofici ${ }^{216}$.

Violó

Jaume SOLER, violó, músic oficial del Capítol, va manifestar a aquest, el 31 d'agost de 1750, que, havent-hi hagut dos oficis, a la capella de la Concepció, a on assistien els oficials, el sagristà major no el volgué convidar a ell, "per no ser official dels de dins" i, com que no entenia què volia dir aquesta expressió, per això demanava al Capítol que determinés quina classe d'oficials havien de ser convidats als oficis celebrats pels oficials del Capítol. El Capítol resolgué que els oficials del Capítol, si eren eclesiàstics, tots eren iguals i havien de ser cridats, d'acord amb llur antiguitat $\mathrm{i}$ orde ${ }^{217}$.

El 29 de juliol de 1754, presentà una súplica al Capítol, acompanyada de fe del metge, amb què demanava llicència i presència per anar a prendre les aigues, cosa que li convenia molt per a la salut. El Capítol li concedí la llicència, però la resolució a la presència l'encarregà als Protectors de la Capella i de la Comuna ${ }^{218}$.

Josep SOLER, violó. També trobem aquest músic, possiblement parent de l'anterior, als llistats dels músics de la Catedral, en la sèrie Caritat. Albarans, per ex., al llibre dels anys 17491751, f. 116.

\title{
Violó contrabaix
}

Bartomeu SABATINI. El 27 de març de 1749, fou admès com a oficial i violó contrabaix de la Capella, aquest músic, el cognom del qual evidencia una procedència italiana, a proposta del Protector de la Capella ${ }^{219}$.

A l'acta del 14 d'abril de 1749, el canonge Morera demanava salari i conveniència per al violó contrabaix i per al segon violó, això és, N. Soler, admesos feia poc a la Capella. Fou resolt que se'ls assignés d'acord amb la què tenien llurs antecessors ${ }^{220}$.

El 18 de juny de 1749, el contrabaix Sabatini exposà al Capítol que, no podent mantenirse decentment del que treia de la Capella, i oferint-se-li altra millor conveniència, demanava permís per a acceptar-la. El Capítol li respongué que prengués la decisió que més li podria conve$\operatorname{nir}^{221}$.

\author{
215. SIV. $21, f .138 v$. \\ 216. SIV. 21,f. $141 v$. \\ 217. SIV. 20,f. 203. \\ 218. SIV. 22, f. 24. \\ 219. SIV. 20, f. 135. \\ 220. SIV. 20,f. 136v. \\ 221. SIV. 20,f. $145 v$.
}


Violó gros i també contrabaix de Viola

Jordi MARQUÈS/MARQUET, contrabaix de Viola i violó gros (Caritat. Albarans, 17471749 , f. 111). És interessant l'acta que comentaré tot seguit, del dia 21 de juny de 1748 , perquè ens indica la qualitat, no sols dels músics, sinó que també dels instruments emprats en la nostra Catedral, en aquesta ocasió el violó contrabaix i l'import del mateix. Efectivament, la vídua de Jordi Marquet, oficial i músic de la Capella de música de la Catedral, exposà al Capítol que el violó contrabaix del seu marit, difunt, era de grans veus, y dels q.e millor han reheixit, i per això l'oferia, en primer lloc al Capítol, per no tenir del difunt altra millor alaja, tot esperant que el Capítol li abonaria les 14 dobles que valia i esperava que l'ajudessin, també, amb alguna gratificació per poder sufragar sos dols. El Capítol deixà en mans del Protector de la Capella, l'adquisició del violó, si el considerava útil per a la Capella, i que ho fés privadament, però per compte de la Catedral. Ara bé, considerà que l'ajuda que demanava la vídua, no tenia lloc, per no haver-hi cap exemplar ${ }^{222}$. La resposta del Capítol fou donada el 9 de setembre següent, en el sentit de comprar el susdit instrument, deixant la gestió a mans del Protector dels escolans i a condició que fos destinat al servei de la Catedral i de la Capella de música ${ }^{223}$.

El 20 de desembre de 1748, es féu manament a favor del Procurador de la Manna i contra la Caritat, de 56 lliures, per a pagar el Contrabaix Violó, instrument que pertanyia a Jordi Marquès (sic), del qual import es retindria allò que es devia de la funerària del susdit Marquès i la diferència seria donada a la vídua ${ }^{224}$.

El 23 de gener de 1750, fou llegida una súplica del Mestre de Capella, en la qual manifestava que no era convenient proveir l'ofici de contrabaix-violó i, al mateix temps, foren llegides quatre súpliques de tants altres pretenents. Es resolgué que encara no es proveeria dit instrument ${ }^{225}$. 